\title{
ANNOTATIONS
}

\section{The Lighting of Post Offices}

A Committee has recently issued a valuable report on the lighting conditions and their effects on the work and health of the employees in post offices in the U.S.A. An abstract of this report is published in the Illuminating Engineer for April. It well illustrates, as the editor of that journal points out, the good effects attending the co-operation of the physicist and the ophthalmic surgeon. The Committee consisted of Drs. J. E. Ives, L. R. Thomson, Louis Schwartz, and, as scientific assistant, Mr. N. P. Bryan. Parenthetically we might point out that in the Committee appointed to perform a similar task for the Royal Navy (see review in the June number of this journal) it was not considered necessary to include any ophthalmologist.

The nature of the tests undertaken fall into three main groups : (1) Occupational and process studies; (2) illumination tests; (3) studies of defects of eyesight amongst post office operators. Several points of interest are to be noted in group 3, amongst others the occurrence of a number of cases of nystagmus. As an explanation it is stated that the variation in illumination was considerable, and that even when the average value was relatively high, the range for the same process was excessive, values well below one foot-candle being frequently recorded. A letter-separator (? sorter) reads on an average between thirty and forty addresses a minute. and his work may require adjustment of the ocular muscles as much as eighty times a minute. The Committee records that the acuteness of vision is usually lower for the letter-separators than for employees generally and that this discrepancy tends to increase with years of service. "It appears, therefore, that the intensive eyework done in this department tends to cause more rapid deterioration of vision." This statement seems to claim that a healthy eye can be injured by intensive work. We should be inclined to think that the cause for the deterioration is more likely to be found in the defective illumination conditions described in the report. An interesting commercial calculation is given in which it is pointed out in detail how in one particular institution the cost of raising the lighting value from 3.6 to 8 foot-candles would be about 1 per cent. of the wages bill, while the increased efficiency would probably reach about 4.4 per cent. of that sum. The report concludes with a series of recommendations, one of which is to the effect that the eyes of post office workers should be examined annually by an eye specialist and any defects recorded and corrected. We fear it would be too much to hope that our own post office might adopt that suggestion. 